\title{
Progression of the smoking epidemic in high-income regions and its effects on male-female survival differences: a cohort- by-age analysis of 17 countries
}

Maarten Wensink ${ }^{1,2^{*}+}$ D , Jesús-Adrián Alvarez ${ }^{1+}$, Silvia Rizzi ${ }^{1,2}$, Fanny Janssen ${ }^{3,4}$ and Rune Lindahl-Jacobsen ${ }^{1,2}$

\begin{abstract}
Background: Of all lifestyle behaviours, smoking caused the most deaths in the last century. Because of the time lag between the act of smoking and dying from smoking, and because males generally take up smoking before females do, male and female smoking epidemiology often follows a typical double wave pattern dubbed the 'smoking epidemic'. How are male and female deaths from this epidemic differentially progressing in high-income regions on a cohort-by-age basis? How have they affected male-female survival differences?

Methods: We used data for the period 1950-2015 from the WHO Mortality Database and the Human Mortality Database on three geographic regions that have progressed most into the smoking epidemic: high-income North America, high-income Europe and high-income Oceania. We examined changes in smoking-attributable mortality fractions as estimated by the Preston-Glei-Wilmoth method by age (ages 50-85) across birth cohorts 1870-1965. We used these to trace sex differences with and without smoking-attributable mortality in period life expectancy between ages 50 and 85 .
\end{abstract}

Results: In all three high-income regions, smoking explained up to $50 \%$ of sex differences in period life expectancy between ages 50 and 85 over the study period. These sex differences have declined since at least 1980, driven by smoking-attributable mortality, which tended to decline in males and increase in females overall. Thus, there was a convergence between sexes across recent cohorts. While smoking-attributable mortality was still increasing for older female cohorts, it was declining for females in the more recent cohorts in the US and Europe, as well as for males in all three regions.

Conclusions: The smoking epidemic contributed substantially to the male-female survival gap and to the recent narrowing of that gap in high-income North America, high-income Europe and high-income Oceania. The precipitous decline in smoking-attributable mortality in recent cohorts bodes somewhat hopeful. Yet, smokingattributable mortality remains high, and therefore cause for concern.

Keywords: Sex differences, Life expectancy, Smoking epidemic, Mortality, Health inequality

\footnotetext{
* Correspondence: mwensink@health.sdu.dk

+Maarten Wensink and Jesús-Adrián Álvarez contributed equally to this work.

${ }^{1}$ Interdisciplinary Centre on Population Dynamics, University of Southern

Denmark, Odense, Denmark

${ }^{2}$ Department of Public Health, University of Southern Denmark, Odense,

Denmark

Full list of author information is available at the end of the article
}

(c) The Author(s). 2020 Open Access This article is distributed under the terms of the Creative Commons Attribution 4.0 International License (http://creativecommons.org/licenses/by/4.0/), which permits unrestricted use, distribution, and reproduction in any medium, provided you give appropriate credit to the original author(s) and the source, provide a link to the Creative Commons license, and indicate if changes were made. The Creative Commons Public Domain Dedication waiver (http://creativecommons.org/publicdomain/zero/1.0/) applies to the data made available in this article, unless otherwise stated. 


\section{Background}

According to the Global Burden of Disease Study, in 2015 worldwide, one out of ten deaths was due to smoking [1]. The same data suggest that smoking is the single most important killer in the world with nearly twice as many victims as the 5\% deaths from AIDS, malaria and tuberculosis combined [2]. As such, the smoking epidemic is having a huge impact on the world population and on the individual risk of transitioning to the worst possible health condition, i.e. to die [3].

The enormous increase and subsequent decline in smoking prevalence and later smoking-attributable mortality, and sex differences therein, has been described in detail and termed the 'smoking epidemic' $[4,5]$. The smoking epidemic model describes that men in high-income countries (particularly the AngloSaxon countries) were the first to take up smoking and that smoking-attributable mortality rose some three decades after the rise in smoking prevalence. Women began to smoke later in time than males. Attention for the negative health effects of smoking and associated prevention campaigns led the proportion of males that smoke to decline and the peak in the smoking prevalence among women to be considerably lower than for men. Because of the various time lags, there is a stage where the proportion of males dying from smoking begins to decline, but the proportion of females continues to rise (Fig. 1) $[4,5]$.

In the 1950 s, over $50 \%$ of males in the United States (US) were smokers. By 2015, this had changed to less than $20 \%$. For females, these numbers were $24 \%$ in the 1950 s, versus $12-15 \%$ currently [6-11]. For Europe this pattern was similar $[7,8]$. Because the percentages of smokers for males versus females are first divergent, then convergent, in line with the theoretical model outlined above and in Fig. 1, and because high-income countries have progressed furthest into the smoking epidemic, we aimed to chart the progression of deaths from smoking in high-income North-America, highincome Europe and high-income Oceania, as well as the way these deaths have influenced male-female survival differences.

The cohort perspective has been helpful in understanding the unfolding of the smoking epidemic [12]. Also, smoking has been shown to be a significant driver of sex differences in survival [13-18]. Hence, we performed a cohort-by-age analysis of smoking-attributable mortality and investigated its effect on male-female life expectancy differences. We hypothesized that the smoking epidemic may have been the main contributor to the widening and subsequent narrowing of the male-female survival gap in high-income regions in the second half of the twentieth century. We also hypothesized that the cohort perspective could reveal important aspects of the smoking epidemic.

\section{Methods}

All-cause death rates and person-years at risk by age, sex, year and country were retrieved from the Human Mortality Database (HMD) [19], which collects these data from national registries worldwide and, after quality control, publishes these in a uniform format [20]. To estimate smoking-attributable mortality (see below), we used lung cancer deaths, defined as malignant neoplasms of trachea, bronchus and lung classified according to the International Statistical Classification of Diseases,

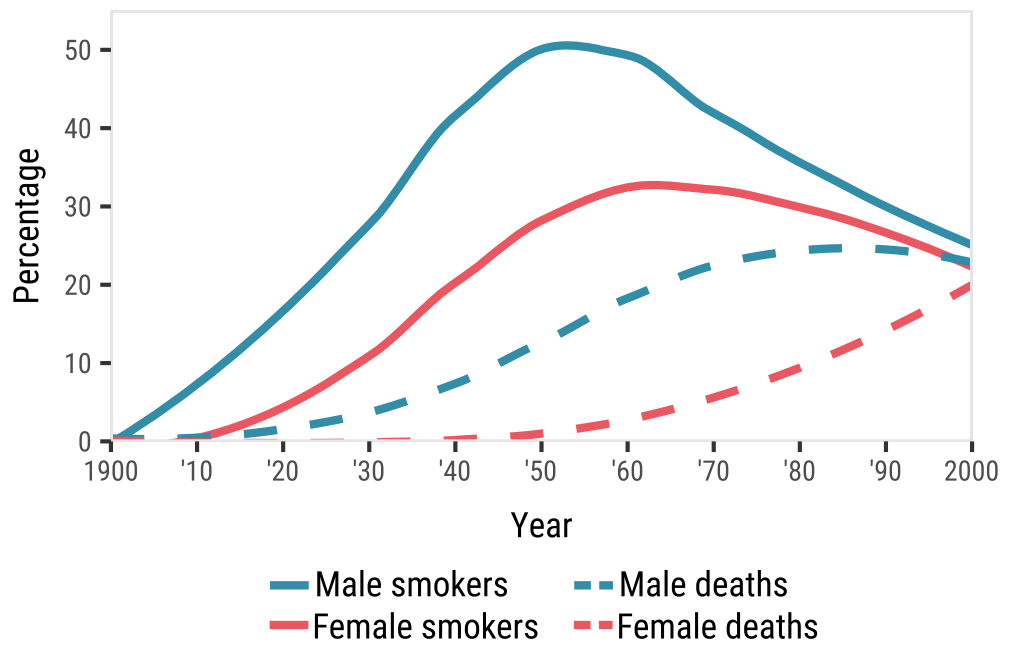

Fig. 1 Schematic diagram of smoking epidemic, after reference 5. Males (in blue) take up smoking (solid line) at a steady pace until smokingattributable mortality surges (dashed line) and the proportion smoking starts to decline. Females (in red) take up smoking later than males and reach a lower maximum proportion smoking. Smoking-attributable mortality in females is the last to increase to significant proportions. An essential feature of the model is the large time gap between the act of smoking and dying from it 
Injuries and Causes of Death versions 7 through 10 (ICD-7: 162, 163; ICD-8 and ICD-9: 162; ICD-10: C33, C34). Death counts from lung cancer were retrieved from the World Health Organization (WHO) Mortality Database [21]. Their cause-of-death statistics come from national vital registration systems. The information is compiled by the national authority and submitted to WHO every year. WHO verifies that the data submitted are coded with the official ICD codes [21].

Mortality data by age (50-85 years) and sex for the populations of 17 high-income countries during the period 1950-2015 were used. The focus on age 50 and over stems from the technique that we used to indirectly estimate smoking-attributable mortality (see below). This method relies on deaths from lung cancer, which are generally rare below age 50 [22]. Furthermore, previous research has shown that most of male-female mortality differences are concentrated between ages 50 and 70 [13].

The method that we used to estimate smokingattributable mortality, the Preston-Glei-Wilmoth (PGW) method [23] (see below), was based on 20 high-income countries from around the world. We used much the same data set, but we added recent data and excluded three countries. We excluded Iceland because of its geographical location between Europe and North America. We excluded countries that spent much of the 19502015 period behind the Iron Curtain, because the countries missed out on the cardiovascular revolution for decades, a phenomenon sometimes called the state socialist syndrome [24]. This led us to exclude Hungary. Japan was excluded because of its atypical smoking history [25]. For Portugal, cause-specific mortality data were not available for the period 2004-2006. We imputed death rates for males and females for Portugal during the period 2004-2006 (3 observations per sex in total, details in Additional file 1) by taking into account all the remaining information about death rates since 1950. We use a non-parametric method based on random forest algorithms to perform the imputation ("missForest" $\mathrm{R}$ package, version 1.4 [26])". The 17 remaining countries were grouped into three geographical categories: high-income North America (US and Canada), highincome Europe (Austria, Belgium, Denmark, Finland, France, Italy, the Netherlands, Norway, Portugal, Spain, Sweden, Switzerland and the UK), and high-income Oceania (Australia and New Zealand).

The Preston-Glei-Wilmoth (PGW) method [23] was used to appraise the proportion of deaths attributable to smoking. This method assumes that "after adjusting for sex and age, smoking is the only source of variation in lung cancer death rates in the populations under consideration" [23]. It estimates smoking attributable deaths indirectly by assuming that lung cancer rates of smokers and never-smokers match those observed among individuals in the Cancer Prevention Study II in the US. The model then uses negative binomial regression to model smoking attributable mortality from causes other than lung cancer as a function of lung cancer mortality [23]. An analysis of deviance to assess the model fit is included in the Additional file 1.

We then smoothed smoking-attributable mortality estimates with the penalized composite link model [27], giving year-by-age estimates of the proportions of death due to smoking for all 17 countries for males and females over age 50 . We used such year-by-age estimates to construct birth-cohorts' mortality profiles between 1870 and 1965 for high-income North America, highincome Europe and high-income Oceania [28]. Thus we obtained the proportion of smoking-attributable mortality by sex, cohort and age (cohorts 1870-1965).

To shed light on how smoking-attributable mortality affected period life expectancy, the way in which the sex gap in survival is often analyzed [13], we calculated period life expectancy between ages 50 and $85\left(e_{50 \mid 85}\right.$, the average number of years lived between ages 50 and 85) over the period 1950-2015 following standard demographic procedures [29]. This measure is defined as follows:

$$
e_{50 \mid 85}=\frac{\sum_{50}^{85} l(x)}{l(50)},
$$

where $l(x)$ denotes number of survivors at age $\mathrm{x}$. We applied the life table calculations to all-cause mortality rates (including smoking-attributable mortality) and to non-smoking-attributable mortality rates (excluding smoking-attributable mortality) for the three regions and the different years. From those results we calculated male-female $e_{50} \mid 85$ differences for all regions and periods.

All analyses were run on $\mathrm{R}$ version 3.6.

\section{Results}

Between 1950 and 2015, the smoking epidemic caused a total of 39 million deaths at ages $50-85$ in the three high-income geographical locations. Of these, 29 million deaths were men and 10 million were women. The largest numbers of deaths attributable to smoking were in high-income North America with 13 million men and 7 million women, followed by high-income Europe with 15 million and 3 million, respectively. In high-income Oceania these numbers were 0.7 million and 0.2 million.

For males in high-income Europe, North America and Oceania, we found a steep increase in the proportion of smoking-attributable mortality from the cohorts born 
1870 up to about 1900-1910, when smoking-attributable mortality was the highest (Fig. 2). For high-income North America and Oceania, after reaching a peak for the 1910-1930 cohorts, there was a large drop in the proportion of smoking-attributable mortality in more recent cohorts. For Europe, the upsurge was followed by a stagnation period up to the most recent cohorts, where a steep drop was seen.

For females in high-income North America, the upsurge in smoking-attributable mortality was delayed by about 30 years relative to males (Fig. 2). At the highest ages, which are necessarily older cohorts, the peak in the proportion of smoking-attributable mortality does not seem to have been reached as yet, although some indication exists. For the younger ages, the peak was reached for the 1930 cohorts, with a steep decline after, interrupted only by the 1950 cohorts. For European females, smoking-attributable mortality increased less steeply and peaked later and lower than for North-American females. Any decline in smoking-attributable mortality in European females is seen in the most recent cohorts only, necessarily at younger ages. At higher ages, the proportion of smoking-attributable mortality is still on the increase. For Oceania, the pattern was similar to that of the Europe, but without any significant drop to date.

In terms of absolute levels of smoking-attributable mortality (rather than trends), smoking-attributable mortality was higher in males than for females in Europe for all age groups and all cohorts, even though for recent cohorts the absolute differences were small (Fig. 2). For the US and Oceania, smoking-attributable mortality was higher for males than for females for most cohorts and age groups, in particular those that drove recent changes. However, for recent cohorts at relatively young ages, smoking-attributable mortality was similar between sexes, even slightly higher for females than for males.

We produced an alternative version of Fig. 2 with age on the horizontal axis and each birth cohort represented by a line (Additional file 1: Figure S3), providing a complementary perspective of the smoking epidemic in the high-income regions.

The effect of removing smoking-attributable mortality on $e_{50} \mid 85$ was similar for the three regions. For males, it increased gradually for the years $\sim 1950-1970$, to up to $\sim 2$ years of partial life expectancy (Fig. 3, top panels). This was particularly pronounced for Belgium, The Netherlands and the UK, while the increase was smallest for Sweden (Additional file 1: Figure S4). In the following years the effect of removing smoking-attributable mortality on $e_{50 \mid 85}$ remained more or less constant for some decades until approximately 1990. Afterward it declined to $\sim 1$ year for recent years. For females, the effect of removing smoking-attributable mortality on $e_{50 \mid 85}$ was negligible for the years 1950-1970. Afterwards it

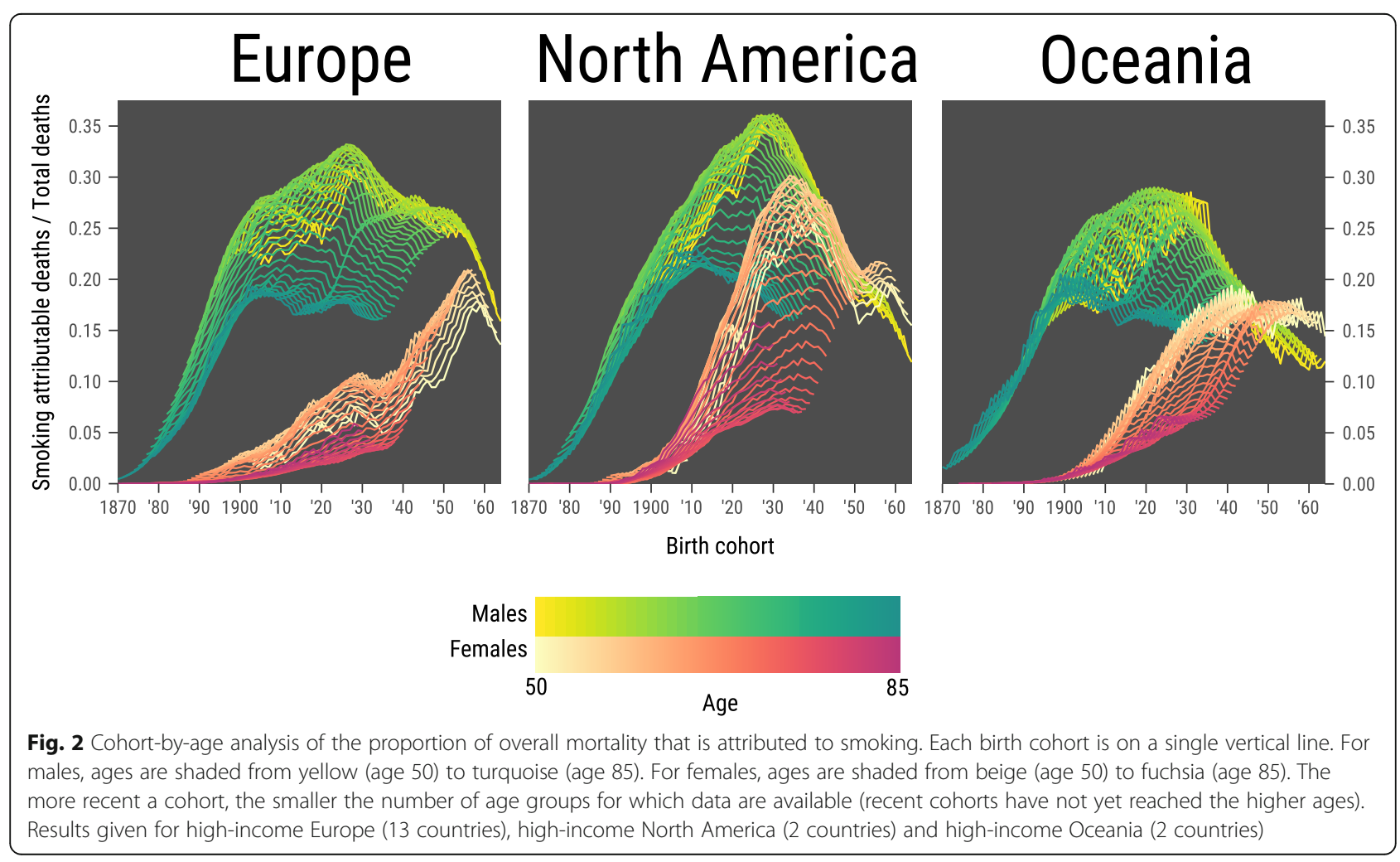



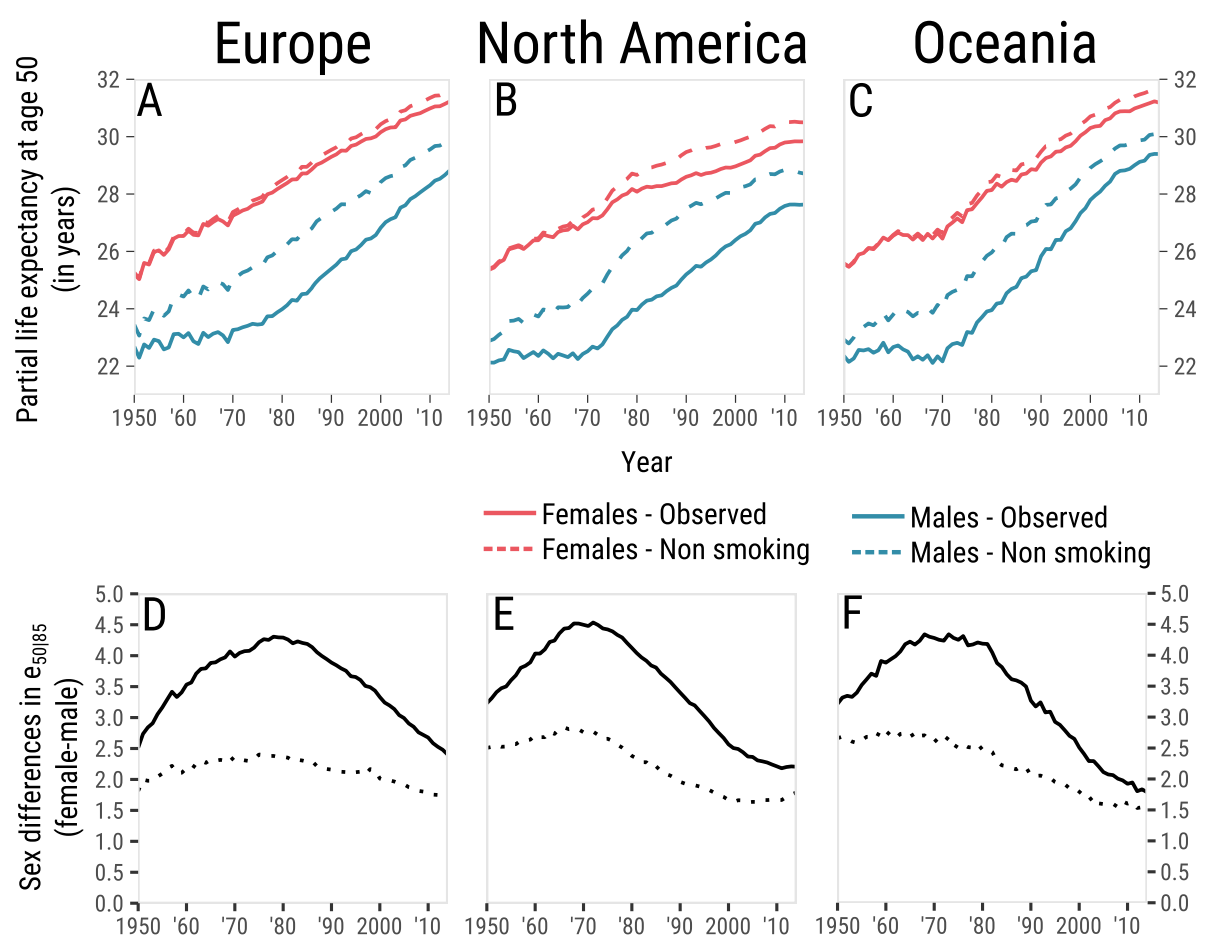

Year

- Total population ...... Non-smoking attributable mortality

Fig. 3 Upper panel: Historical development of period life expectancy between ages 50 and 85 ( $e_{50}$ | 85, in years) for males (blue) and females (red) with the observed mortality rates (solid), and when smoking-attributable mortality was omitted (dashed), for the three studied regions. Lower panel: Sex differences in period $e_{50} \mid 85$ with observed mortality (total population), and when smoking-attributable mortality was removed, for the three studied regions

grew slowly but steadily to $\sim 0.5$ year. This was particularly pronounced in the US, but less so in Europe and Oceania.

Globally, over all three regions, the sex gap in $e_{50} \mid 85$ was approximately 3 years in 1950, then increased to some 4.5 years around 1975, and afterwards decreased towards 2 years (Fig. 3, bottom panels). Omitting smoking-attributable deaths, the male-female difference in $e_{50}$ | 85 would have been approximately 2 years lower at its peak and much more constant over time than with smoking included (Fig. 3, bottom panels).

The contribution of smoking to male-female differences in life expectancy is now on the decline (Figs. 2 and 3). In some countries (Italy, New Zealand, Finland, Spain), this is due to declining smoking attributable mortality in males. In other countries (Sweden, Norway, Iceland), this is mainly due to increasing smokingattributable mortality in females. Finally, there are countries (Canada, Austria, UK, US, Netherlands, Australia) where the decline is caused by an approximately equal contribution to each side of the $e_{50 \mid 85}$ gap (Additional file 1: Figure S5).

\section{Discussion}

Our study advanced three main results. First, in all three high-income regions, smoking explained up to $50 \%$ of sex differences in period life expectancy between age 50 and 85 over the study period 1950-2015. Second, the decline in these sex differences since approximately 1980 is largely driven by smoking-attributable mortality. Third, whereas smoking-attributable mortality is still increasing for many older female cohorts, it is declining for females in the more recent cohorts in the US and Europe, as well as for males in all three regions.

The massive impact of smoking on mortality is in line with previous studies addressing smoking effects on mortality at the population level; it has been found for the United States [14], in European countries [12, 15, 30-35], and worldwide [36]. Smoking affects various causes of death, such as various forms of cancer, cardiovascular disease and multifarious diseases of the respiratory tract [37, 38]. Smoking also explains important differences in life expectancy between countries [39]. Finally, the historical trajectories of divergence between life expectancy with and without smoking-attributable 
mortality that we found are broadly similar to those previously found for specific countries [40].

\section{Insights into the smoking epidemic across cohorts}

Our cohort-by-age analysis of high-income regions confirmed the mortality element of the smoking epidemic model $[4,5]$ : the increase in smoking-attributable mortality started later among females than for males, and resulted in a later peak at a lower level. Without constructing cohort profiles, we would not have been able to trace two additional important regularities of the smoking epidemic. First, while smoking-attributable mortality in older cohorts still increased, a precipitous decline in smoking-attributable mortality took place in recent cohorts at younger ages. Second, smokingattributable mortality for males versus females converged across cohorts.

The continuous increase in smoking-attributable mortality in older female cohorts remains cause for concern. It is an essential feature of the smoking epidemic, though, that these deaths result from the high smoking prevalence of women decades ago. More encouraging is the decline in smoking-attributable mortality in recent cohorts at younger ages. Also, smoking prevalence has generally come down over the last decades in the studied regions. For example, in Australia smoking prevalence in females aged $15+$ came down from $22.0 \%$ in 2000 to $12.4 \%$ in 2015 (for males, these numbers were 27 and $14.3 \%$, respectively) [41].

In the same vein, current sex-specific smoking prevalence gives some indication of future sex-specific smoking attributable mortality. In 2015 smoking prevalence generally remained higher in males than in females. For example, in $201532 \%$ of French men smoked, versus $22 \%$ of females; in Germany, $25 \%$ of males smoked versus $17 \%$ of females; while in the US $14 \%$ of males smoked versus $12 \%$ of females [7]. Consequently, male smoking-attributable mortality is likely to remain (or become again) higher than female smoking-attributable mortality.

\section{The smoking epidemic and the sex gap in life expectancy} In 1950 the sex gap in period $e_{50} \mid 85$ was $2.0-3.5$ years. It subsequently grew to $4.3-4.5$ years at the maximum around 1970-1980, and then decreased to $1.8-2.5$ years in 2015 for the three regions. The rise, stagnation and decline in the sex differences in survival has been described in detail elsewhere [13, 16-18]. Smoking behaviour has been found to explain international differences in the life expectancy sex gap [42-44]. We here show that across high-income regions, almost no increase in the sex gap would have occurred without smokingattributable mortality. Smoking-attributable mortality caused almost all the increase and most of the decrease in the sex gap over the study period.

Although the major part of the decline in the sex gap hitherto is caused by the steep drop in smokingattributable mortality in males, more and more so this is also due to the increases in smoking-attributable mortality in females overall. For all-causes mortality, in contrast, it has been found that a reduction in the malefemale life expectancy gap is, for most countries, due to men dying at lower rates, rather than women at higher rates $[18,45]$.

We suggest that we may not have seen the end of the narrowing in $e_{50} \mid 85$ sex differences in these regions yet. To date, male smoking-attributable mortality generally still exceeds that of females. Meanwhile, trends are downward for males generally, while for females they are upwards for older cohorts. This suggests scope for further narrowing sex differences in $e_{50} \mid 85$ in these regions. However, the extent to which this may happen seems limited because male smoking prevalence generally remains higher nowadays than female smoking prevalence (see above). Of course, smoking-attributable mortality is not the only factor that affects the sex gap, and there is evidence that mortality from some causes other than smoking may currently be widening the gap [16]. Still, smoking-attributable mortality could overwhelm the effect of mortality from other causes on the sex gap. This could happen especially in countries with a high proportion of women taking up smoking some decades ago, where smoking-attributable mortality for men and women could potentially cross over (e.g. U.K., Denmark and the Netherlands) [8], as we have found for the most recent cohorts in the US and Oceania.

\section{Limitations}

One clear limitation of our study is the indirect calculation of the smoking-attributable deaths. Such a limitation is unavoidable: comparisons between different methods to estimate smoking-attributable mortality did not reveal a best-practice method [46, 47], and even if good estimates of smoking prevalence are available to potentially directly estimate smokingattributable mortality, other factors like smoking intensity are often harder to measure and to take into account in direct estimates.

Since the PGW method [23] extrapolates the lung cancer rates of non-smokers from a US study to other countries, there may be a bias in our estimates for those other countries. Also, the PGW is based on study participants that are more likely than the US overall population to be Caucasian and middle class, and to have achieved a relatively high level of education [47]. However, previous analyses have shown that the indirect estimation by PGW resulted in roughly similar 
outcomes compared to other indirect estimation techniques $[30,31,48]$, so we are confident that our results are broadly reliable. Results obtained making a modification to the PGW method proposed by Rostron [49], discussed in [50], are included in the Additional file 1. Making this modification would not have affected our main conclusion.

As a final limitation, our estimates of smokingattributable mortality were smoothed over ages, which may lead to minor distortions. We do not expect that to be the case here due to relatively regular source data.

\section{Conclusion}

While a sharp decrease in recent cohorts is a strong positive development, smoking-attributable mortality for both sexes has converged across cohorts to a level that remains high. Males and females dying of smoking at the same rate is not an end to the smoking epidemic. In high-income regions, smoking remains a major killer.

\section{Supplementary information}

Supplementary information accompanies this paper at https://doi.org/10. 1186/s12889-020-8148-4

\section{Additional file 1. Appendix.}

\section{Abbreviations}

HMD: Human Mortality Database; ICD: International Statistical Classification of Diseases, Injuries and Causes of Death; PGW: Preston, Glei, Wilmoth; WHO: World Health Organization

\section{Acknowledgements}

The authors gratefully acknowledge the comments made by the reviewers as well as the editor on earlier versions of this manuscript.

\section{Authors' contributions}

MW drafted the paper with help from JA, FJ and RL. JA and SR performed data analysis. RL conceived of the study. All authors critically interpreted and discussed the results. All authors read and approved the manuscript.

\section{Funding}

The contribution by FJ is funded by the Netherlands Organisation for Scientific Research (NWO) in relation to the research programme "Smoking, alcohol, and obesity, ingredients for improved and robust mortality projections", under grant no. 452-13-001. See www.futuremortality.com. The work of MW, J-AA, SR and RL-J was supported by the US National Institutes of Health (2P01AG031719). Funding bodies had no role in inception, design, interpretation or publication of the results.

\section{Availability of data and materials}

All data are publicly available from the Human Mortality Database (www. mortality.org) and the WHO Mortality Database (http://www.who.int/ healthinfo/mortality_data/en/).

\section{Ethics approval and consent to participate}

All data are publicly available on an aggregate basis. Consequently, no ethics approval was necessary.

\section{Consent for publication}

Not applicable.

\section{Competing interests}

The authors declare that they have no competing interests.

\section{Author details}

Interdisciplinary Centre on Population Dynamics, University of Southern Denmark, Odense, Denmark. ²Department of Public Health, University of Southern Denmark, Odense, Denmark. ${ }^{3}$ Population Research Centre, Faculty of Spatial Sciences, University of Groningen, Groningen, The Netherlands. ${ }^{4}$ Netherlands Interdisciplinary Demographic Institute, The Hague, The Netherlands.

Received: 23 August 2019 Accepted: 31 December 2019

Published online: 10 January 2020

\section{References}

1. GBD 2015 Tobacco Collaborators MB, Fullman N, Ng M, et al. Smoking prevalence and attributable disease burden in 195 countries and territories, 1990-2015: a systematic analysis from the Global Burden of Disease Study 2015. Lancet. 2017;389:1885-906.

2. Wang $H$, Naghavi $M$, Allen $C$, et al. Global, regional, and national life expectancy, all-cause mortality, and cause-specific mortality for 249 causes of death, 1980-2015: a systematic analysis for the global burden of disease study 2015. Lancet. 2016;388:1459-544.

3. World Health Organization. WHO report on the global tobacco epidemic, 2017: monitoring tobacco use and prevention policies. https://www.who. int/tobacco/global_report/2017/en/. Accessed 26 Jan 2019.

4. Lopez AD, Collishaw NE, Piha T. A descriptive model of the cigarette epidemic in developed countries. Tob Control. 1994;3:242-7.

5. Thun M, Peto R, Boreham J, Lopez AD. Stages of the cigarette epidemic on entering its second century. Tob Control. 2012;21:96-101.

6. Brandt AM. The cigarette century: the rise, fall, and deadly persistence of the product that defined America. New York: Basic Books; 2007.

7. tobaccoatlas.org, respective country information sheets, Accessed 1 Nov 2019.

8. Graham H. Smoking prevalence among women in the European Community 1950-1990. Soc Sci Med. 1996;43:243-54.

9. Centers for Disease Control and Prevention (CDC). Tobacco Use - United States, 1900-1999. Morb Mortal Wkly Rep. 1999;48:986-93.

10. United States Public Health Service. Office of the Surgeon General, Office on Smoking and Health. The health consequences of smoking: a report of the Surgeon General. 2004.

11. World Bank Open Data. 2017. https://data.worldbank.org/indicator/SH.PRV. SMOK.FE. Accessed 15 Mar 2018.

12. Lindahl-Jacobsen R, Oeppen J, Rizzi S, Möller S, Zarulli V, Christensen K, Vaupel JW. Why did Danish women's life expectancy stagnate? The influence of interwar generations' smoking behaviour. Eur J Epidemiol. 2016; 31:1207-11.

13. Beltrán-Sánchez H, Finch CE, Crimmins EM. Twentieth century surge of excess adult male mortality. Proc Natl Acad Sci. 2015;112:8993-8.

14. Preston HP, Wang H. Sex mortality differences in the United States: the role of cohort smoking patterns. Demography. 2006;43:631-46.

15. Lew EA, Garfinkel L. Differences in mortality and longevity by sex, smoking habits and health status. Transac Soc Actuaries. 1987:39:107-30.

16. Pampel FC. Cigarette use and the narrowing sex differential in mortality. Popul Dev Rev. 2002;28:77-104.

17. Thorslund M, Wastesson JW, Agahi N, Lagergren M, Parker MG. The rise and fall of women's advantage: a comparison of national trends in life expectancy at age 65 years. Eur J Ageing. 2013;10:271-7.

18. Meslé F. Life expectancy: a female advantage under threat? Popul Soc. 2004 402:1-4.

19. Human Mortality Database. https://www.mortality.org/. Accessed 20 Sept 2018.

20. Barbieri M, Wilmoth JR, Shkolnikov VM, Glei D, Jasilionis D, Jdanov D, Boe C, Riffe T, Grigoriev P, Winant C. Data resource profile: the human mortality database (HMD). Int J Epidemiol. 2015;44:1549-56.

21. World Health Organization. Health statistics and information systems 2018 http://www.who.int/healthinfo/mortality_data/en/. Accessed 20 Sept 2018.

22. National Cancer Institute. SEER: Cancer statistics and facts: Iong and bronchus cancer. https://seer.cancer.gov/statfacts/html/lungb.html. Last accessed 25 Mar 2019.

23. Preston SH, Glei DA, Wilmoth JR. A new method for estimating smokingattributable mortality in high-income countries. Int J Epidemiol. 2010;39: $430-8$. 
24. Józan P. Crisis and renewal in epidemiological development after world war II in Hungary. Budapest: MTA Társadalomkutató Központ; 2008.

25. Honjo K, Kawachi I. Effects of market liberalisation on smoking in Japan. Tob Control. 2000;9:193-200

26. Stekhoven DJ, Bühlmann P. MissForest-non-parametric missing value imputation for mixed-type data. Bioinformatics. 2011;28:112-8.

27. Rizzi S, Gampe J, Eilers P. Efficient estimation of smooth distributions from coarsely grouped data. Am J Epidemiol. 2015;182:138-47.

28. Carstensen B. Age-period-cohort models for the Lexis diagram. Stat Med. 2007;26:3018-45.

29. Preston SH, Heuveline P, Guillot M. Demography. Measuring and modeling population processes. Oxford: Blackwell Publishers; 2001.

30. Stoeldraijer $L$, Bonneux $L$, van Duin $C$, van Wissen $L J G$, Janssen $F$. The future of smoking-attributable mortality: the case of England \& Wales, Denmark and the Netherlands. Addiction. 2015:110:336-45.

31. Janssen F, van Wissen $\sqcup G$, Kunst AE. Including the smoking epidemic in internationally coherent mortality projections. Demography. 2013;50:134162.

32. Lindahl-Jacobsen R, Rau R, Jeune B, et al. Rise, stagnation, and rise of Danish women's life expectancy. Proc Natl Acad Sci. 2016;113:4015-20.

33. Jacobsen $R$, Keiding $N$, Lynge E. Long term mortality trends behind low life expectancy of Danish women. J Epidemiol Community Health. 2002;56:205-8.

34. Jacobsen R, Von Euler M, Osler M, Lynge E, Keiding N. Women's death in Scandinavia - what makes Denmark different? Eur J Epidemiol. 2004;19:117-21.

35. Jacobsen R, Keiding N, Lynge E. Causes of death behind low life expectancy of Danish women. Scand J Public Health. 2006;34:432-6.

36. Rentería E, Jha P, Forman D, Soerjomataram I. The impact of cigarette smoking on life expectancy between 1980 and 2010: a global perspective. Tob Control. 2016:25:551-7.

37. WHO, Cancer IAfRo. Personal Habits and Indoor Combustions Volume 100e A Review Of Human Carcinogens. IARC Monogr Eval Carcinog Risks Hum. 2012;100:1-441.

38. Aburto JM, Wensink M, van Raalte $\mathrm{A}$, Lindahl-Jacobsen R. Potential gains in life expectancy by reducing inequality of lifespans in Denmark: An international comparison and cause-of-death analysis. BMC Public Health. 2018;18:831

39. Janssen F. (provisionally accepted) The role of smoking in country differences in life expectancy across Europe, 1985-2014. Nicotine Tob Res.

40. Janssen F, Rousson V, Paccaud F. The role of smoking in changes in the survival curve: an empirical study in 10 European countries. Ann Epidemiol. 2015;25:243-9.

41. WHO (2015) Global report on trends in tobacco smoking 2000-2025 - First edition.

42. Bobak M. Relative and absolute gender gap in all-cause mortality in Europe and the contribution of smoking. Eur J Epidemiol. 2003;18:15-8.

43. Janssen F. (forthcoming) Changing contribution of smoking to the sex differences in life expectancy in Europe. Eur J Epidemiol.

44. Janssen F. Similarities and Differences Between Sexes and Countries in the Mortality Imprint of the Smoking Epidemic in 34 Low-Mortality Countries, 1950-2014. Nicotine Tob Res. 2019;ntz154. https://doi.org/10.1093/ntr/ ntz154.

45. Meinow B, Parker M, Thorslund M. Complex health problems and mortality among the oldest old in Sweden: decreased risk for men between 1992 and 2002. Eur J Ageing. 2010;7:81-90.

46. Pérez-Ríos M, Montes A. Methodologies used to estimate tobaccoattributable mortality: a review. BMC Public Health. 2008;8:22.

47. Tachfouti N, Raherison C, Obtel M, Nejjari C. Mortality attributable to tobacco: review of different methods. Arch Public Health. 2014;72:22.

48. Martikainen P, Makela P, Peltonen R, Myrskyla M. Income differences in life expectancy: the changing contribution of harmful consumption of alcohol and smoking. Epidemiology. 2014;25:182-90.

49. Rostron B. A modified new method for estimating smoking-attributable mortality in high-income countries. Demogr Res. 2010;23:399-420.

50. Fenelon A, Preston SH. Estimating smoking-attributable mortality in the United States. Demography. 2012;49:797-818.

\section{Publisher's Note}

Springer Nature remains neutral with regard to jurisdictional claims in published maps and institutional affiliations.

\section{Ready to submit your research? Choose BMC and benefit from:}

- fast, convenient online submission

- thorough peer review by experienced researchers in your field

- rapid publication on acceptance

- support for research data, including large and complex data types

- gold Open Access which fosters wider collaboration and increased citations

- maximum visibility for your research: over $100 \mathrm{M}$ website views per year

At BMC, research is always in progress.

Learn more biomedcentral.com/submissions 